\title{
A Study of the Optimum Quenching Temperature of Steels with Various Hot Rolling Microstructures after Cold Rolling, Quenching and Partitioning Treatment
}

\author{
Bin Chen ${ }^{1,2,3}$, Juhua Liang ${ }^{2,3}$, Tao Kang ${ }^{2,3}$, Ronghua Cao ${ }^{2,3}$, Cheng $\mathrm{Li}^{2,3}$, Jiangtao Liang ${ }^{2,3}$, \\ Feng Li ${ }^{2,3}$, Zhengzhi Zhao ${ }^{2,3, *}$ and Di Tang ${ }^{2,3}$ \\ 1 Institute of Engineering Technology, University of Science and Technology Beijing, Beijing 100083, China; \\ hellovipkk@126.com \\ 2 Collaborative Innovation Center of steel Technology, University of Science and Technology Beijing, \\ Beijing 100083, China; liangjuhua0721@126.com (J.L.); 13220101686@163.com (T.K.); \\ crhhb@foxmail.com (R.C.); lc18805591994@163.com (C.L.); liangjtao@126.com (J.L.); \\ b20160477@xs.ustb.edu.cn (F.L.); tangdi@nercar.ustb.edu.cn (D.T.) \\ 3 Beijing Laboratory for Modern Transportation Advanced Metal Materials and Processing Technology, \\ University of Science and Technology Beijing, Beijing 100083, China \\ * Correspondence: ustbzzz@126.com; Tel.: +86-10-6233-2617
}

Received: 4 June 2018; Accepted: 24 July 2018; Published: 26 July 2018

\begin{abstract}
Quenching and partitioning (Q\&P) processes were applied to a cold-rolled high strength steel (0.19C-1.26Si-2.82Mn-0.92Ni, wt \%). The effects of the prior hot-rolled microstructure on the optimum quenching temperature of the studied steels were systematically investigated. The microstructure was analyzed by means of transmission electron microscope (TEM), electron backscatter diffraction (EBSD) and X-ray diffraction (XRD). Compared with the ferrite pearlite mixture matrix, the lower martensite start (Ms) temperature and smaller prior austenite grain size in the cold-rolled martensite matrix are the main reasons for the optimum quenching temperature shifting to a lower temperature in the Q\&P steels. We found that an empirical formula that only considers the influence of the alloy composition in the calculation of the Ms temperature will cause a certain interference to the pre-determined optimum quenching temperature of the Q\&P steel.
\end{abstract}

Keywords: quenching and partitioning (Q\&P); martensite matrix; Ms temperature; prior austenite grain

\section{Introduction}

Advanced high-strength steels (AHSS) are widely used in automobiles to ensure good fuel economy and safety. Quenching and partitioning steel (Q\&P steel), one of the representative steels of the third generation of AHSS, promises a further improvement of the mechanical properties via moderate microstructural design [1-4]. The Q\&P process includes two steps, the quenching and partitioning processes. The mixed microstructure of martensite and untransformed retained austenite is first obtained in the quenching stage by adjusting the quenching temperature between the martensite strat (Ms) temperature and martensite finish (Mf) temperature. The subsequent partitioning is commonly carried out at a temperature slightly higher than the quenching temperature in order to stabilize the retained austenite through carbon partitioning from supersaturated martensite. The microstructure of fully austenitized Q\&P steel, including stable retained austenite and carbon-depleted martensite ensures the high strength and plasticity of Q\&P steel.

A large number of studies of Q\&P steels have focused on the effect of the quenching and partitioning parameters on the microstructure and mechanical properties of Q\&P steels [5-8]. 
The exploration of the composition of Q\&P steel alloys is mainly concentrated on low alloy systems. The improvement of austenite-stabilizing elements, especially the increase of the manganese content, has been proved to be beneficial to obtaining a greater proportion of retained austenite [9-13] at room temperature, thereby obtaining good mechanical properties.

Reference [14] describes a quantitative study of the relationship between the multiphase microstructure and mechanical properties. A good correlation between the fraction of initial martensite (or primary martensite or tempered martensite) and the yield strength was obtained. Generally, the proportion of primary martensite is determined by the quenching temperature. The constrained carbon equilibrium (CCE) model [2] can be used to predict the endpoint of the carbon partitioning to austenite. The optimum quenching temperature, which will contribute to a maximum amount of retained austenite, is usually predicted in combination with the Koistinen-Marburger (K-M) relationship [15]. However, the inaccuracy of the K-M relationship for finding the proportion of martensite, the inevitable precipitation of carbides in the complex multicomponent alloy composition system [16,17], austenite/martensite interfacial migration $[18,19]$ and other factors that may affect the Ms temperature prediction, such as austenite grain size [20] and heterogeneous alloying elements, can affect the accuracy of the prediction. The CCE balance equation can be used as a reference for experimental design, while the final retained austenite fraction must be verified by experimental methods such as electron backscatter diffraction (EBSD) and X-ray diffraction (XRD).

In fact, the best mechanical properties depend not only on the respective proportions of each phase but also on the grain size and the grain distribution and morphology. The presence of coarse martensite laths leads to early strain localization, especially when they are in the vicinity of untempered martensite islands [21]. The excessive inhomogeneous microstructure and blocky retained austenite with low stability accelerate the failure of the material with Mn segregation banding. In contrast, fine lath-like ferrites with a greater contact ratio to the surrounding martensites improve the microstructural homogeneity during the pre-quenching process, and results in optimal mechanical properties [22]. Besides, the microstructure prior to Q\&P may also the affect the subsequent evolution of the microstructure, and a fine prior austenite grain at a low austenitizing temperature contributes to a large volume fraction of retained austenite, especially the blocky retained austenite along the prior grain boundaries, and effectively improves the uniformity of the microstructure [23]. In the present work, the influence of three different types of hot-rolled microstructure on the final cold-rolled quenching and partitioning steel were systematic studied, especially the rational design of the optimum quenching temperature, and its relationship to the prior austenite grain size inherited from the three different matrixes.

\section{Experiment}

\subsection{Optimum Quenching Temperature Selection}

The composition of the investigated steel studied in this work was $0.19 \mathrm{C}-1.26 \mathrm{Si}-2.82 \mathrm{Mn}-0.92 \mathrm{Ni}$ (wt \%). The material was smelted in a vacuum induction furnace and cast into a bullet-shaped cast iron mold. The $25 \mathrm{~kg}$ bullet-shaped ingot was heated above $1000{ }^{\circ} \mathrm{C}$ and hot-forged into several rectangular ingots $\left(30 \mathrm{~mm} \times 75 \mathrm{~mm} \times 100 \mathrm{~mm}\right.$ ) for convenient rolling. The ingots were homogenized at $1200{ }^{\circ} \mathrm{C}$ for $1 \mathrm{~h}$, then were hot rolled to a final thickness of $2.8 \mathrm{~mm}$ with an open rolling temperature of $1150^{\circ} \mathrm{C}$ and a finishing temperature of $900{ }^{\circ} \mathrm{C}$, acceleration cooled by water jets to $660^{\circ} \mathrm{C}$ and transferred to a furnace for coiling simulations. The microstructure after hot-rolling consisted of ferrite and pearlite (FPM). A $2 \times 20 \times 400 \mathrm{~mm}^{3}$ rectangular specimen (with the oxide layer removed by machining both surfaces) was cut from the hot-rolled plate mentioned above, then cold-rolled to $1.2 \mathrm{~mm}$.

Before the quenching and partitioning process, the austenite formation temperatures (Ac1 and Ac3)and Ms temperature were measured using the dilatometric method, as shown in Table 1. A $\varphi 4 \times 10 \mathrm{~mm}^{2}$ specimen machined from the ingot was heated at $0.05{ }^{\circ} \mathrm{C} / \mathrm{s}$ to $1000{ }^{\circ} \mathrm{C}$ for $10 \mathrm{~min}$ followed by cooling at $50{ }^{\circ} \mathrm{C} / \mathrm{s}$ to room temperature on a dilatometer machine (DIL805A, 
BAHR-Thermoanalyse GmbH, Hullhorst, Germany). According to previous studies [23,24], treatment at a temperature close to Ac3 can refine the austenite grain size. Thus, the austenitizing parameter of the investigated steel was selected as $820^{\circ} \mathrm{C}$ for $5 \mathrm{~min}$. All the samples were partitioned at $400{ }^{\circ} \mathrm{C}$ for $5 \mathrm{~min}$. The optimum quenching temperature was selected by both theoretical calculations and experimental simulations.

Table 1. Phase transformation parameters.

\begin{tabular}{cccc}
\hline Phase Transformation Parameters & $\mathrm{Ac} 1 /{ }^{\circ} \mathrm{C}$ & $\mathrm{Ac} 3 /{ }^{\circ} \mathrm{C}$ & $\mathrm{Ms} /{ }^{\circ} \mathrm{C}$ \\
\hline value & 723 & 803 & 334 \\
\hline
\end{tabular}

The optimum quenching temperature $\left(201^{\circ} \mathrm{C}\right)$ was first calculated using the CCE model combined with the empirical relation (Equation (1)) [25-27] and K-M relationship (Equation (2)), as shown in Figure 1.

$$
\begin{gathered}
\mathrm{M}_{\mathrm{s}}=539-42300 \mathrm{C}-3040 \mathrm{Mn}-750 \mathrm{Si}-1770 \mathrm{Ni} \\
\mathrm{f}_{\mathrm{M}}^{\mathrm{T}_{\mathrm{q}}}=1-\mathrm{e}^{-1.1 \times 10^{-2}\left(\mathrm{M}_{\mathrm{s}}-\mathrm{T}_{\mathrm{q}}\right)}
\end{gathered}
$$

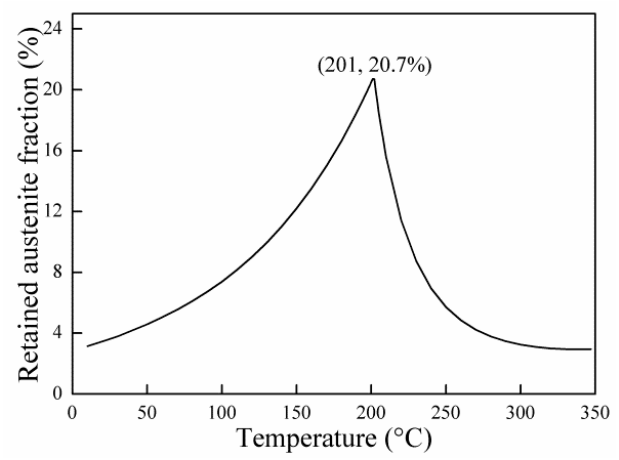

Figure 1. Theoretical calculation of the optimum quenching temperature.

Five different temperatures were designed to obtain different primary martensite fractions based on the K-M relationship, as shown in Figure 2. The corresponding quenching temperature and the primary martensite fraction were $125^{\circ} \mathrm{C}(90 \%), 190{ }^{\circ} \mathrm{C}(80 \%), 250{ }^{\circ} \mathrm{C}(60 \%), 290{ }^{\circ} \mathrm{C}(40 \%)$ and $315{ }^{\circ} \mathrm{C}(20 \%)$. In subsequent $\mathrm{X}$-ray diffraction tests, the three temperature $\left(190{ }^{\circ} \mathrm{C}, 250{ }^{\circ} \mathrm{C}\right.$ and $\left.290{ }^{\circ} \mathrm{C}\right)$ specimens with the highest retained austenite fraction were subjected to tensile tests. Therefore, the optimum quenching temperature was finally confirmed as $190{ }^{\circ} \mathrm{C}$, contributing to the best mechanical properties.

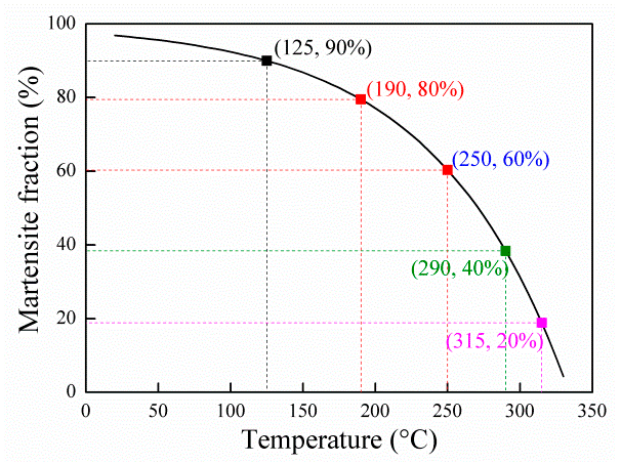

Figure 2. Different primary martensite fractions based on the K-M relationship. 


\subsection{Preparation and Heat Treatment Parameters of the Three Matrixes}

The above microstructure after hot-rolling consisted of ferrite and pearlite (FPM). In this article, we designed another two different microstructures, fresh martensite matrix (FMM) and tempered martensite matrix $(\mathrm{TMM})$. A $2 \times 20 \times 400 \mathrm{~mm}^{3}$ rectangular specimen was cut from a hot-rolled plate, as mentioned above, then heated at $5^{\circ} \mathrm{C} / \mathrm{s}$ to $850{ }^{\circ} \mathrm{C}$ and held for $5 \mathrm{~min}$, before finally being cooled at $50{ }^{\circ} \mathrm{C} / \mathrm{s}$ to room temperature using a continuous annealing simulator (CCT-AY-II, Ulvac-Riko INC., Tokyo, Japan) to obtain the fresh martensite matrix. The other specimen was subjected to the same quenching process, and then tempered at $400{ }^{\circ} \mathrm{C}$ for $5 \mathrm{~min}$ to obtain the tempered martensite matrix. These specimens were also cold-rolled to $1.2 \mathrm{~mm}$. Since the cold rolling reduction rate did not exceed $50 \%$, cracking did not occur at the edge of the cold-rolled sheet. The tensile strength of each sample was measured and recorded using a tensile test before cold rolling. Correspondingly, the tensile strength of the FPM sample was $1094 \mathrm{MPa}$, that of the FMM sample was $1884 \mathrm{MPa}$, and that of the TMM sample was $1554 \mathrm{MPa}$.

The quenching and partitioning processes (which was the same for the FPM sample with a quenching temperature of $190^{\circ} \mathrm{C}$ ) were applied to the FMM and TMM cold-rolled plates. Additional dilatometer tests were performed to better analyze the differences in the mechanical properties. The corresponding martensite start (Ms) temperatures were measured under the same austenitizing parameters. Specifically, the $4 \times 10 \mathrm{~mm}^{2}$ rectangular specimens of three matrix cold-rolled plates were heated at $5{ }^{\circ} \mathrm{C} / \mathrm{s}$ to $820^{\circ} \mathrm{C}$ and held for $5 \mathrm{~min}$, and finally cooled at $50{ }^{\circ} \mathrm{C} / \mathrm{s}$ to room temperature. The entire experimental design roadmap and specific heat treatment parameters are shown in Figure 3. In addition, the heat treatment and tensile tests at lower quenching temperatures, such as $160^{\circ} \mathrm{C}$, were also added to the FMM and TMM samples to support our conclusions.

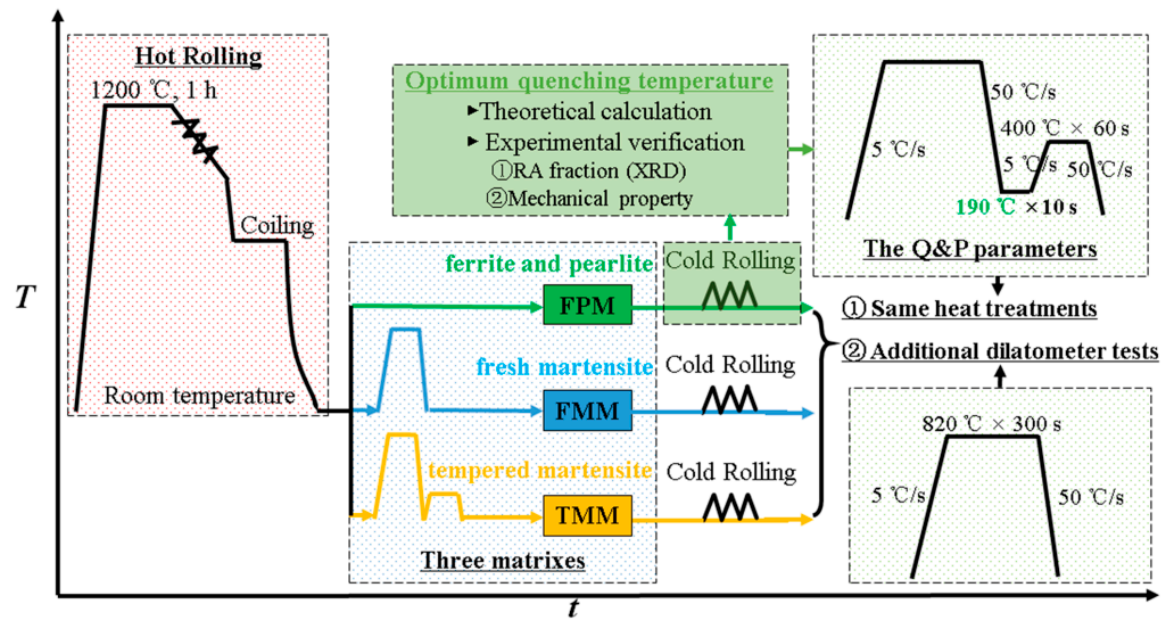

Figure 3. Entire experimental design roadmap and specific heat treatment parameters.

\subsection{Testing Parameters}

The tensile properties were obtained using the uniaxial tensile test, which was performed at a crosshead speed of $1.0 \mathrm{~mm} / \mathrm{min}$ with a gauge length of $25 \mathrm{~mm}$. The twin-jet polishing technique (5\% perchlorate alcohol at $-30^{\circ} \mathrm{C}$, applied potential of $50 \mathrm{~V}$ ) was implemented to prepare thin foil samples for the TEM observation (JEM 2100, Japan Electronics Co., Ltd., Tokyo, Japan)). Electron backscatter diffraction (EBSD) was performed on the samples with a step size of $0.05 \mu \mathrm{m}$ using a Zeiss ULREA 55-type field emission electron scanning electron microscopy (Zeiss ULREA 55-type, Oberkochen, Germany) equipped with an HKL Nirdlys F+ probe (OXFORD Instruments, Oxford, UK). X-ray diffraction (XRD) was performed on the D/MAX-RB (Rigaku Corporation, Tokyo, Japan) operating at $45 \mathrm{kV}$ and $150 \mathrm{~mA}$, and the $2 \theta$ containing the three austenite peaks $(\{200\},\{220\}$ and $\{311\})$ and two martensite peaks $(\{200\},\{211\})$ were scanned in order to estimate the fraction of retained austenite with 
a step size of $0.02^{\circ}$ using $\mathrm{Cu}-\mathrm{K}_{\alpha}$ radiation. The austenite lattice parameter $\mathrm{a}_{\gamma}\left(10^{-1} \mathrm{~nm}\right)$ of the samples was determined by the position of the maximum of each austenite reflection, and the manganese content $x_{\mathrm{Mn}}(\mathrm{wt} \%$ ) was considered to be homogeneous and constant in the steel. Thus, the average carbon concentration $x_{c}(w t \%)$ of the austenite was approximately obtained by using the equations provided in $[28,29]$, while the influence of $\mathrm{Si}$ and $\mathrm{Ni}$ on the lattice parameters of austenite was assumed to negligible. The surface of the samples for the EBSD and XRD tests were electrolytically polished in a mixture reagent of $20 \%$ perchloric acid and $80 \%$ ethanol with a voltage of $15 \mathrm{~V}$ for $20-30 \mathrm{~s}$.

$$
\mathrm{a}_{\gamma}=3.556+0.0453 \mathrm{x}_{\mathrm{c}}+0.00095 \mathrm{x}_{\mathrm{Mn}}
$$

\section{Results and Discussion}

\subsection{Optimum Quenching Temperature}

The average carbon content and fraction of retained austenite under different quenching temperatures was detected by XRD, as shown in Figure 4. The average carbon content of the retained austenite increased with the decrease of the quenching temperature. The different primary martensite fractions influenced by the various quenching temperatures account for the phenomenon. With the decreasing quenching temperature, more primary martensite formed in the first quenching process. The carbon enrichment of the retained austenite occurred more easily during the partitioning process, since the higher primary martensite fraction at the lower quenching temperature ensures sufficient carbon diffusion into the retained austenite. In terms of the sample quenched at $315{ }^{\circ} \mathrm{C}$, the lowest primary martensite fraction of $20 \%$, estimated by the K-M relationship during the first quenching process, can hardly provide sufficient carbon to stabilize the retained austenite with a fraction of $80 \%$ during the partitioning process. Therefore, it has the lowest average carbon content.
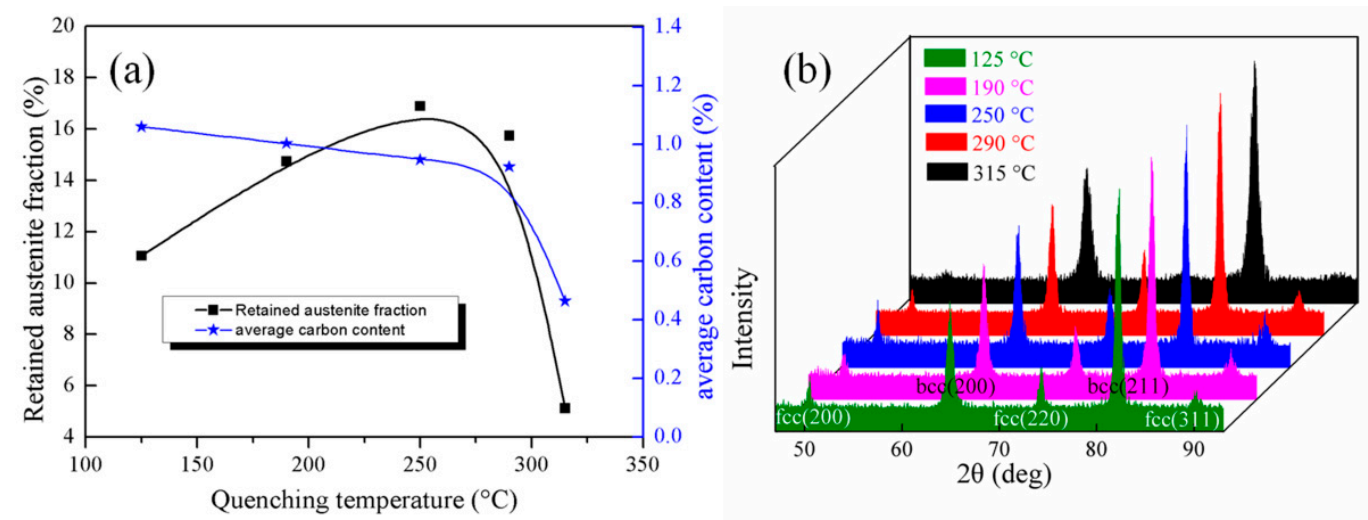

Figure 4. Retained austenite fractions and average carbon content under different quenching temperatures (a) and the corresponding X-ray diffraction patterns (b).

The difference in results between the retained austenite fraction obtained through theoretical calculation (Figure 1) and practical (XRD) measurement (Figure 4) is expected. As mentioned earlier, both the inevitable precipitation of carbides and austenite/martensite interfacial migration are neglected in the CCE model, and the deviation of the K-M equation itself in the prediction of the martensite fraction as well as the computing error of the Ms temperature by the empirical relation (Equation (1)) will all affect the accuracy of the theoretical calculation shown in Figure 1. In addition, as shown in the TEM photographs (Figure 5), the presence of floc-like carbides inside the tempered martensite laths in the FPM190 sample also demonstrates the inevitability of carbide formation during the partitioning process. Although the quenching temperature varied from $190^{\circ} \mathrm{C}$ to $290{ }^{\circ} \mathrm{C}$, the retained austenite fraction of all three samples remained at a similar level (above $14 \%$ ). The corresponding mechanical properties after the tensile tests are shown in Figure 6. Although there 
is no highest retained austenite content in FPM190, it exhibits good overall mechanical properties with both a tensile strength exceeding $1400 \mathrm{MPa}$ and a total elongation exceeding $15 \%$. The lower quenching temperature of $190{ }^{\circ} \mathrm{C}$ resulted in the higher primary martensite fraction after the quenching process. Accordingly, the prior austenite grains were divided into the smaller retained austenite grains. Similar conclusions were reported in a previous paper [30]. In other words, the more primary martensite, the smaller the retained austenite grain size. Therefore, the stability of the retained austenite can be enhanced. The microstructure under the EBSD experiment, as shown in Figure 7, fits well with this explanation. Compared with the microstructure of FPM190, there is significantly more large-sized blocky fresh martensite in FPM250 and FPM290. The higher quenching temperatures of $250{ }^{\circ} \mathrm{C}$ and $290^{\circ} \mathrm{C}$ result in a lower primary martensite fraction after the quenching process. Thus, unlike the small austenite grains divided by the primary martensite in FPM190, the large-sized blocky austenite will be retained in both FPM250 and FPM290. During the subsequent partitioning process, these large-sized blocky austenite grains, if not fully carbon-enriched and stabilized, will become fresh martensite in the second quenching process. The presence of such blocky fresh martensite is the main reason for the premature failure of materials [31,32], and should be avoided in Q\&P steels in order to obtain better mechanical properties.

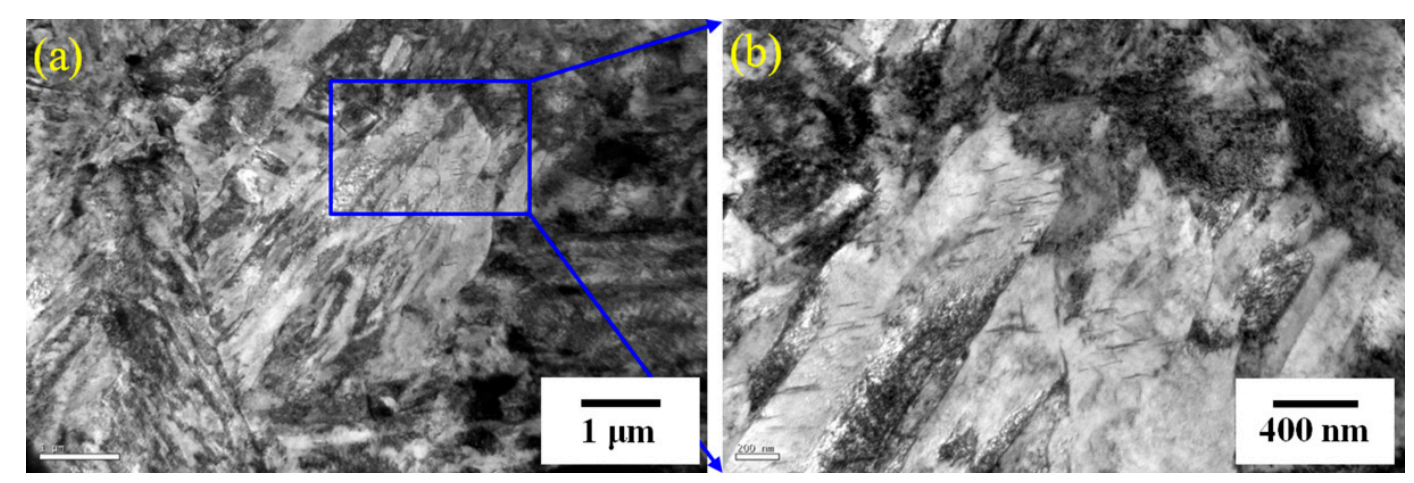

Figure 5. Transmission electron micrographs of the FPM190 sample. The blue area in (a) is partially enlarged in (b), showing the floc-like carbides existing in the martensite lath.

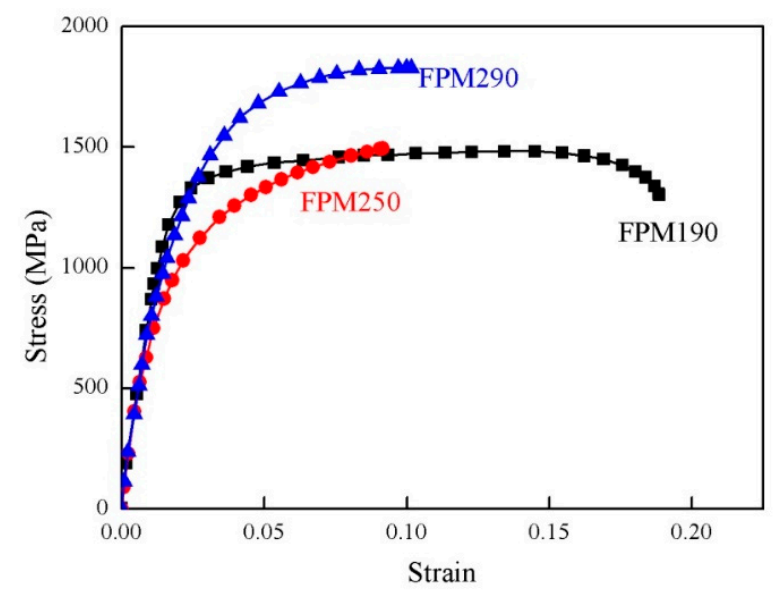

Figure 6. Engineering stress-strain curves of the ferrite and pearlite matrix after the Q\&P process under different quenching temperatures. 


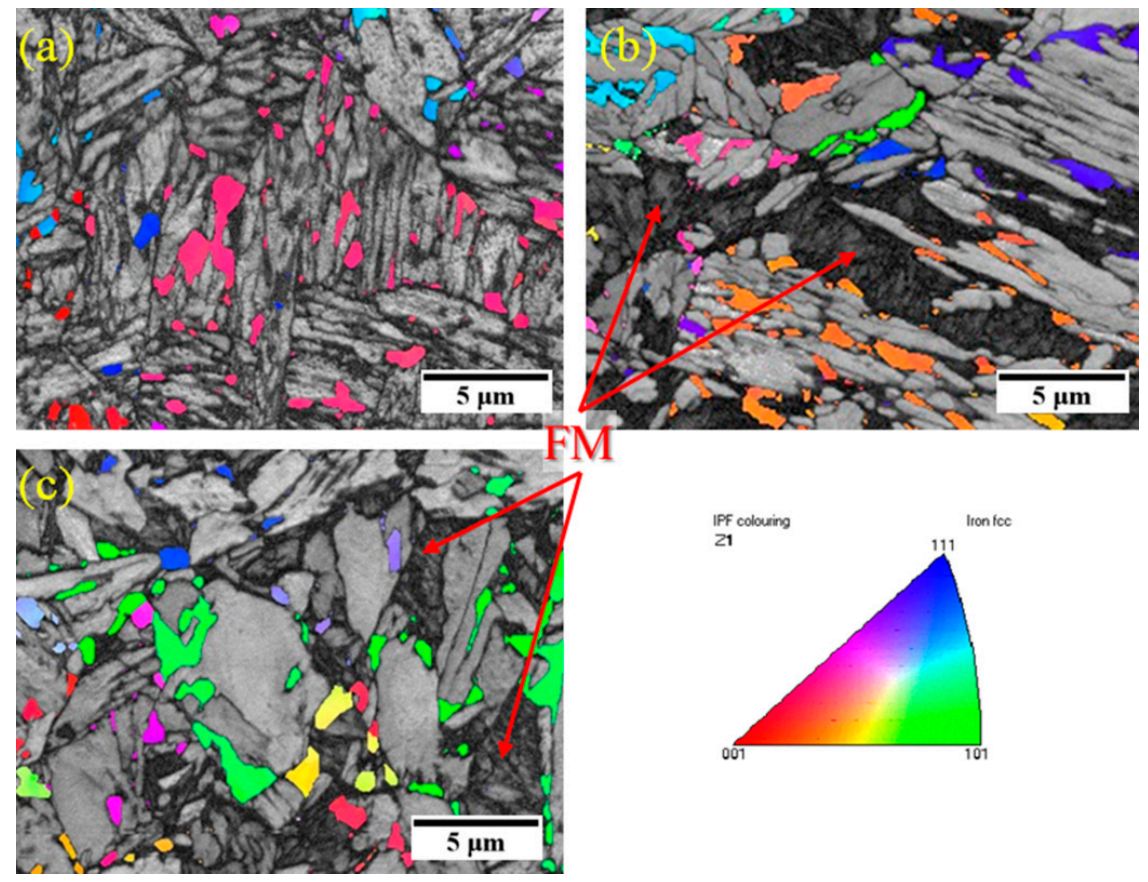

Figure 7. Electron backscatter diffraction analysis results of the samples (a) FPM190, (b) FPM250, (c) FPM290, combined band-contrast map of martensite and an orientation map of retained austenite; The inset shows the inverse pole-figure map for the austenite phase in $(\mathbf{a}-\mathbf{c})$. The "FM" denotes the fresh martensite.

\subsection{Ms Temperature and Microstructure Characterization under Different Matrixes}

The same heat treatment process with an optimum quenching temperature of $190^{\circ} \mathrm{C}$ was applied to the respective cold-rolled plates of three different hot-rolled microstructures. It is worth noting that the mechanical properties of both the fresh martensite and tempered martensite matrix samples were totally different from the ferrite and pearlite matrix sample, as shown in Figure 8. Another lower quenching temperature of $160^{\circ} \mathrm{C}$ was added for further investigation, the tensile properties of which are also shown in Figure 8. It is evident that the overall mechanical properties of the FMM and TMM samples significantly improved as the quenching temperature was reduced to $160^{\circ} \mathrm{C}$. This means that the optimum quenching temperature was likely to have shifted to lower temperatures in both the fresh martensite and tempered martensite matrix samples.

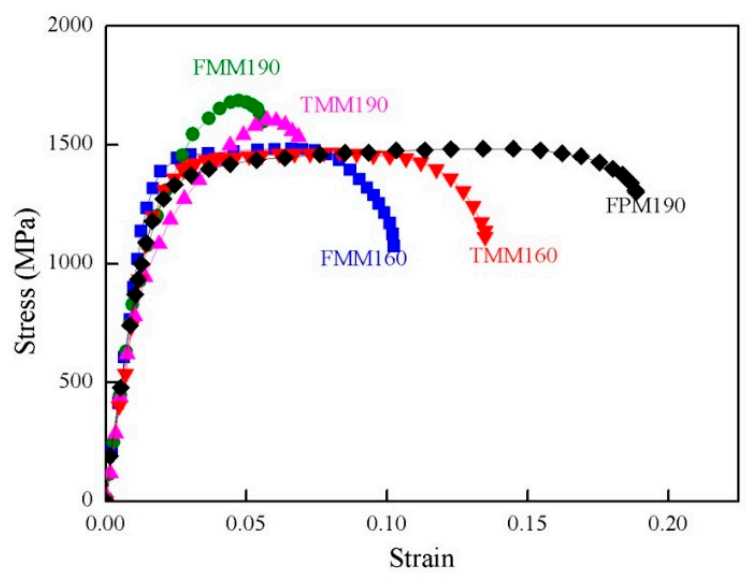

Figure 8. Engineering stress-strain curves of three different matrixes after the Q\&P process. 
The dilatometer results of the three matrix cold-rolled microstructures also accounts for the abovementioned tensile properties and the fact that the optimum quenching temperature shifted to a lower temperature. After the same austenitizing treatment and subsequent rapid cooling to room temperature, the corresponding Ms temperatures of the three samples exhibited different values, as shown in Figure 9. The Ms temperatures of both the FMM and TMM samples had a similar value of about $281^{\circ} \mathrm{C}$, while the Ms temperature of the FPM sample had the higher value of $315^{\circ} \mathrm{C}$. These values are different from the Ms temperature of $334^{\circ} \mathrm{C}$ of the sample previously machined from the ingot, that is, both the rolling process and the subsequent heat treatment process had a non-negligible effect on the Ms temperature. This change of Ms temperature directly lead to the difference in the optimum quenching temperature of these three different matrix samples.
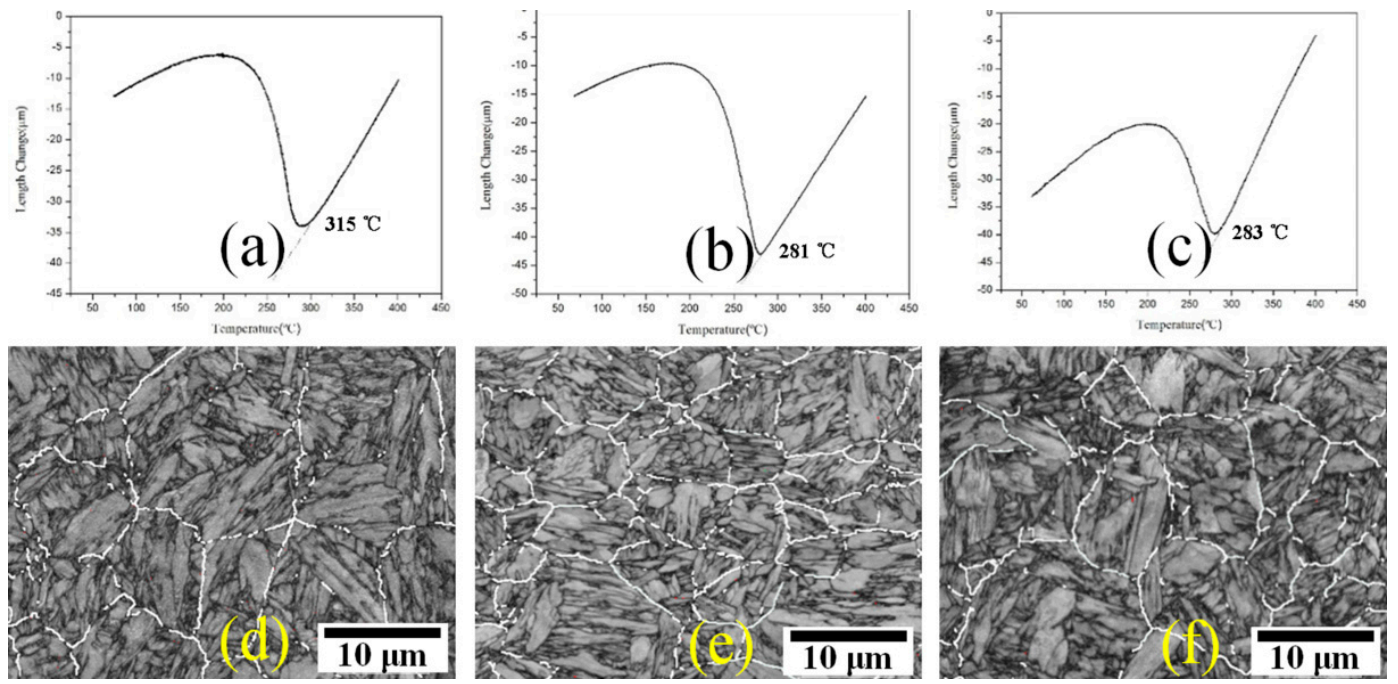

Figure 9. Dilatometric curves and EBSD band-contrast maps of different microstructures after cold rolling (a,d) FPM, (b,e) FMM and (c,f) TMM samples.

As the research indicates [33-35], the Ms temperature decreases with the reduction of the prior austenite size. In order to show the differences in microstructure, we depicted the prior austenite grain with the help of EBSD, as shown in Figure 9. Most of the boundaries created during the martensite transformation were either low angle boundaries $\left(<15^{\circ}\right)$ or high angle boundaries in the range from $50^{\circ}$ to $63^{\circ}$ [36]. Consequently, the possible prior austenite grain boundaries are characterized, with a misorientation between $18^{\circ}$ and $47^{\circ}$, by solid white lines in Figure 9 . The prior austenite grain size of the FPM sample was significantly higher than that of the other two samples, which was consistent with the difference in the Ms temperatures. Therefore, the fine prior austenite grain size resulting from the cold rolling of the martensitic matrix was the main reason for the optimum quenching temperature shifting to a low temperature in the Q\&P steels.

\subsection{Modified Empirical Formula}

We re-examined the accuracy of the method in calculating the optimum quenching temperature using the CCE balance equation and empirical formula. Table 2 shows the Ms temperature measured by the dilatometric method and the Ms temperature provided by the empirical formula; $\Delta \mathrm{T}$ indicates the difference the between the measured value and the calculation results. Subsequently, this difference was introduced into the empirical formula in Equation (1), as shown in Equation (4). The modified empirical formula was combined with the CCE balance equation to re-estimate the optimum quenching temperature. The corresponding results are shown in Figure 10.

$$
\mathrm{M}_{\mathrm{S}}=539-42300 \mathrm{C}-3040 \mathrm{Mn}-750 \mathrm{Si}-1770 \mathrm{Ni}-\Delta \mathrm{T}
$$


Table 2. The measured and calculated Ms temperature.

\begin{tabular}{cccccc}
\hline \multicolumn{4}{c}{ Dilatometric Method } & Empirical Formula \\
\cline { 1 - 4 } Sampling Source & Steel Ingots & $\begin{array}{c}\text { FPM } \\
\text { Cold-Rolled }\end{array}$ & $\begin{array}{c}\text { FMM } \\
\text { Cold-Rolled }\end{array}$ & $\begin{array}{c}\text { TMM } \\
\text { Cold-Rolled }\end{array}$ & (281 \\
\hline $\mathrm{Ms} /{ }^{\circ} \mathrm{C}$ & 334 & 315 & 281 & 283 & 347 \\
$\Delta \mathrm{T} /{ }^{\circ} \mathrm{C}$ & 13 & 32 & 66 & 64 & 0 \\
\hline
\end{tabular}

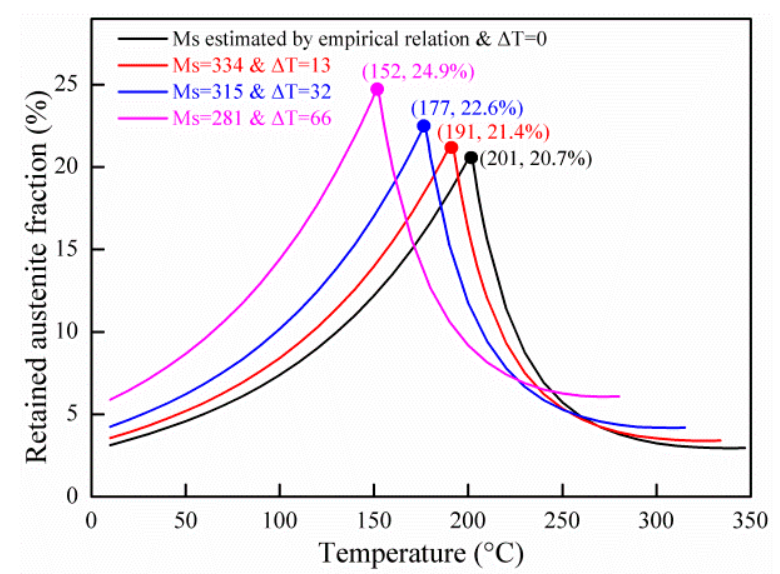

Figure 10. Theoretical calculation of the optimum quenching temperature influenced by different Ms temperatures.

Obviously, for the empirical formula as in Equation (1), simply considering the alloy composition to estimate the Ms temperature is not completely accurate. This difference is also one of the reasons for the difference between the theoretical calculation and the actual optimum quenching temperature. The theoretically calculated optimum quenching temperature varies significantly with the Ms temperature. The optimum quenching temperature is transferred from the highest value of $201{ }^{\circ} \mathrm{C}$ to the lowest temperature of $152{ }^{\circ} \mathrm{C}$, corresponding to the steel ingot sample with a Ms temperature of $334{ }^{\circ} \mathrm{C}$ and the cold-rolled martensite matrix sample with a Ms temperature of $281^{\circ} \mathrm{C}$, respectively. Ignoring the deviation between the theoretical calculation and the actual optimum quenching temperature, we found that there is a certain relationship between the difference in Ms temperature in the three matrix samples and the optimum quenching temperature. Specifically, the actual optimum quenching temperature of $160^{\circ} \mathrm{C}$ for the martensitic matrix sample is about $30^{\circ} \mathrm{C}$ lower than that of $190^{\circ} \mathrm{C}$ for the cold-rolled ferrite pearlite mixture matrix sample. Similarly, the theoretically calculated optimum quenching temperature also had a difference of $25^{\circ} \mathrm{C}\left(177^{\circ} \mathrm{C}-152^{\circ} \mathrm{C}\right)$. Correspondingly, the Ms temperature difference was about $34^{\circ} \mathrm{C}\left(315^{\circ} \mathrm{C}-281^{\circ} \mathrm{C}\right)$. In general, even with the same heat treatment, the three different cold-rolled matrixes of the same alloy composition exhibited different mechanical properties and microstructures, mainly due to differences in the actual optimum quenching temperature and the Ms temperature influenced by the prior austenite grain size.

\section{Conclusions}

In this paper, the effect of different matrixes after cold rolling on subsequent Q\&P parameters was systematically studied. For Q\&P-treated ferrite and pearlite matrix samples, despite having a high retained austenite fraction at both the quenching temperatures of $250{ }^{\circ} \mathrm{C}$ and $290{ }^{\circ} \mathrm{C}$, a large amount of massive blocky fresh martensite is present, leading to premature fracturing during stretching, while at the optimum quenching temperature of $190^{\circ} \mathrm{C}$, the fine uniform microstructure without the fresh martensite contributes to good overall mechanical properties.

The same Q\&P process was applied to the cold-rolled sheet of both fresh martensitic matrix and tempered martensite samples, and the mechanical properties of the three samples exhibited 
significant differences. Various prior austenite grain sizes and Ms temperatures, which were verified by dilatometric curve analysis and EBSD map observation, account for the differences existing in the optimum quenching temperature and the resultant mechanical properties. Compared with the higher Ms temperature of $315^{\circ} \mathrm{C}$ in the cold-rolled ferrite and pearlite matrix sample, the reduction of the Ms temperature in the cold-rolled martensitic matrix samples $\left(281^{\circ} \mathrm{C}\right.$ in $\mathrm{FMM}$ and $\left.283^{\circ} \mathrm{C} \mathrm{TMM}\right)$ is the primary reason for the transfer of the optimum quenching temperature from $190{ }^{\circ} \mathrm{C}$ to $160{ }^{\circ} \mathrm{C}$. Besides, the empirical formula simply considering the alloy composition when estimating the Ms temperature will cause a certain interference to the prediction of actual optimum quenching temperature in the Q\&P steels.

Author Contributions: B.C., J.L., Z.Z., and D.T. conceived and designed the experiments; B.C., T.K., R.C., C.L., J.L. and F.L. performed the experiments; B.C., Z.Z. and J.L. analyzed the data; B.C. and J.L. wrote the paper; Z.Z., F.L. and D.T. improved the language in this paper.

Funding: This research was funded by National Natural Science Foundation of china grant number (51574028) and National Key R\&D Program of China grant number (2017YFB0304401).

Acknowledgments: This research was supported by the National Natural Science Foundation of China (Grant no. 51574028) and National Key R\&D Program of China (2017YFB0304401).

Conflicts of Interest: The authors declare no conflict of interest.

\section{References}

1. Speer, J.; Matlock, D.K.; De Cooman, B.C.; Schroth, J.G. Carbon partitioning into austenite after martensite transformation. Acta Mater. 2003, 51, 2611-2622. [CrossRef]

2. Speer, J.G.; Edmonds, D.V.; Rizzo, F.C.; Matlock, D.K. Partitioning of carbon from supersaturated plates of ferrite, with application to steel processing and fundamentals of the bainite transformation. Curr. Opin. Solid State Mater. Sci. 2004, 8, 219-237. [CrossRef]

3. Speer, J.; Hackenberg, R.; Decooman, B.; Matlock, D. Influence of interface migration during annealing of martensite/austenite mixtures. Philos. Mag. Lett. 2007, 87, 379-382. [CrossRef]

4. Speer, J.; De Moor, E.; Clarke, A. Critical assessment 7: Quenching and partitioning. Mater. Sci. Technol. 2015, 31, 3-9. [CrossRef]

5. Hsu, T.Y.; Jin, X.J.; Rong, Y.H. Strengthening and toughening mechanisms of quenching-partitioningtempering (Q-P-T) steels. J. Alloys Compd. 2013, 577, 568-571.

6. Santofimia, M.J.; Zhao, L.; Sietsma, J. Overview of mechanisms involved during the quenching and partitioning process in steels. Metall. Mater. Trans. A 2011, 42, 3620-3626. [CrossRef]

7. Santofimia, M.J.; Zhao, L.; Petrov, R.; Kwakernaak, C.; Sloof, W.G.; Sietsma, J. Microstructural development during the quenching and partitioning process in a newly designed low-carbon steel. Acta Mater. 2011, 59, 6059-6068. [CrossRef]

8. Sun, J.; Yu, H.; Wang, S.Y.; Fan, Y.F. Study of microstructural evolution, microstructure-mechanical properties correlation and collaborative deformation-transformation behavior of quenching and partitioning (Q\&P) steel. Mater. Sci. Eng. A 2014, 596, 89-97.

9. De Moor, E.; Speer, J.G.; Matlock, D.K.; Kwak, J.H.; Lee, S.B. Effect of carbon and manganese on the quenching and partitioning response of CMnSi steels. ISIJ Int. 2011, 51, 137-144. [CrossRef]

10. Seo, E.J.; Cho, L.; De Cooman, B.C. Application of quenching and partitioning processing to medium Mn steel. Metall. Mater. Trans. A 2015, 46, 27-31. [CrossRef]

11. Kim, J.H.; Seo, E.J.; Kwon, M.H.; Kang, S.; De Cooman, B.C. Effect of quenching temperature on stretch flangeability of a medium Mn steel processed by quenching and partitioning. Mater. Sci. Eng. A 2018, 729, 276-284. [CrossRef]

12. Hou, Z.; Zhao, X.; Zhang, W.; Liu, H.; Yi, H. A medium manganese steel designed for water quenching and partitioning. Mater. Sci. Technol. 2018, 1-8. [CrossRef]

13. De Moor, E.; Speer, J.G.; Matlock, D.K.; Kwak, J.H.; Lee, S.B. Quenching and partitioning of CMnSi steels containing elevated manganese levels. Steel Res. Int. 2012, 83, 322-327. [CrossRef] 
14. Huyghe, P.; Malet, L.; Caruso, M.; Georges, C.; Godet, S. On the relationship between the multiphase microstructure and the mechanical properties of a $0.2 \mathrm{C}$ quenched and partitioned steel. Mater. Sci. Eng. A 2017, 701, 254-263. [CrossRef]

15. Clarke, A.J.; Speer, J.G.; Miller, M.K.; Hackenberg, R.E.; Edmonds, D.V.; Matlock, D.K.; Rizzo, F.C.; Clarke, K.D.; De Moor, E. Carbon partitioning to austenite from martensite or bainite during the quench and partition (Q\&P) process: A critical assessment. Acta Mater. 2008, 56, 6-22.

16. Pierce, D.T.; Coughlin, D.R.; Williamson, D.L.; Clarke, K.D.; Clarke, A.J.; Speer, J.G.; De Moor, E. Characterization of transition carbides in quench and partitioned steel microstructures by Mossbauer spectroscopy and complementary techniques. Acta Mater. 2015, 90, 417-430. [CrossRef]

17. Pierce, D.T.; Coughlin, D.R.; Clarke, K.D.; De Moor, E.; Poplawsky, J.; Williamson, D.L.; Mazumder, B.; Speer, J.G.; Hood, A.; Clarke, A.J. Microstructural evolution during quenching and partitioning of 0.2C-1.5Mn-1.3Si steels with Cr or Ni additions. Acta Mater. 2018, 151, 454-469. [CrossRef]

18. Thomas, G.A.; Speer, J.G. Interface migration during partitioning of Q\&P steel. Mater. Sci. Technol. 2014, 30, 998-1007.

19. De Knijf, D.; Santofimia, M.J.; Shi, H.; Bliznuk, V.; Fojer, C.; Petrov, R.; Xu, W. In situ austenite-martensite interface mobility study during annealing. Acta Mater. 2015, 90, 161-168. [CrossRef]

20. Yang, H.S.; Suh, D.W.; Bhadeshia, H.K.D.H. More Complete Theory for the Calculation of the Martensite-Start Temperature in Steels. ISIJ Int. 2012, 52, 164-166. [CrossRef]

21. Wang, M.M.; Hell, J.C.; Tasan, C.C. Martensite size effects on damage in quenching and partitioning steels. Scr. Mater. 2017, 138, 1-5. [CrossRef]

22. Liang, J.; Zhao, Z.; Tang, D.; Ye, N.; Yang, S.; Liu, W. Improved microstructural homogeneity and mechanical property of medium manganese steel with Mn segregation banding by alternating lath matrix. Mater. Sci. Eng. A 2018, 711, 175-181. [CrossRef]

23. Zhao, Z.; Liang, J.; Zhao, A.; Liang, J.; Tang, D.; Gao, Y. Effects of the austenitizing temperature on the mechanical properties of cold-rolled medium-Mn steel system. J. Alloys Compd. 2017, 691, 51-59. [CrossRef]

24. Cho, L.; Seo, E.J.; De Cooman, B.C. Near-Ac3 austenitized ultra-fine-grained quenching and partitioning (Q\&P) steel. Scr. Mater. 2016, 123, 69-72.

25. Andrews, K.W. Empirical formulae for the calculation of some transformation temperatures. J. Iron Steel Inst. 1965, 721-727.

26. Ishida, K. Calculation of the effect of alloying elements on the Ms temperature in steels. J. Alloys Compd. 1995, 220, 126-131. [CrossRef]

27. Mahieu, J.; De Cooman, B.C.; Maki, J. Phase transformation and mechanical properties of Si-free CMnAl transformation-induced plasticity-aided steel. Metall. Mater. Trans. A 2002, 33, 2573-2580. [CrossRef]

28. Dyson, D.J. Effect of alloying additions on the lattice parameter of austenite. J. Iron. Steel. Inst. 1970, 208, 469-474.

29. Van Dijk, N.H.; Butt, A.M.; Zhao, L.; Sietsma, J.; Offerman, S.E.; Wright, J.P.; van der Zwaag, S. Thermal stability of retained austenite in TRIP steels studied by synchrotron X-ray diffraction during cooling. Acta Mater. 2005, 53, 5439-5447. [CrossRef]

30. Liu, L.; He, B.B.; Cheng, G.J.; Yen, H.W.; Huang, M.X. Optimum properties of quenching and partitioning steels achieved by balancing fraction and stability of retained austenite. Scr. Mater. 2018, 150, 1-6. [CrossRef]

31. Xiong, X.C.; Chen, B.; Huang, M.X.; Wang, J.F.; Wang, L. The effect of morphology on the stability of retained austenite in a quenched and partitioned steel. Scr. Mater. 2013, 68, 321-324. [CrossRef]

32. Wang, C.Y.; Zhang, Y.J.; Cao, W.Q.; Shi, J.; Wang, M.Q.; Dong, H. Austenite/martensite structure and corresponding ultrahigh strength and high ductility of steels processed by Q\&P techniques. Sci. Chin. Technol. Sci. 2012, 55, 1844-1851.

33. Heinze, C.; Pittner, A.; Rethmeier, M.; Babu, S.S. Dependency of martensite start temperature on prior austenite grain size and its influence on welding-induced residual stresses. Comput. Mater. Sci. 2013, 69, 251-260. [CrossRef]

34. Van Bohemen, S.M.C.; Morsdorf, L. Predicting the Ms temperature of steels with a thermodynamic based model including the effect of the prior austenite grain size. Acta Mater. 2017, 125, 401-415. [CrossRef] 
35. Zhu, K.; Magar, C.; Huang, M.X. Abnormal relationship between Ms temperature and prior austenite grain size in Al-alloyed steels. Scr. Mater. 2017, 134, 11-14. [CrossRef]

36. Ryde, L. Application of EBSD to analysis of microstructures in commercial steels. Mater. Sci. Technol. 2006, 22, 1297-1306. [CrossRef] 